\title{
Solvometallurgical Process for the Recovery of Tungsten from Scheelite
}

\author{
Martina Orefice, ${ }^{*} \S$ Viet Tu Nguyen, ${ }^{\S}$ Stijn Raiguel, Peter Tom Jones, and Koen Binnemans
}

Cite This: Ind. Eng. Chem. Res. 2022, 61, 754-764

Read Online

ACCESS | Lلw Metrics \& More | 回 Article Recommendations | SI Supporting Information

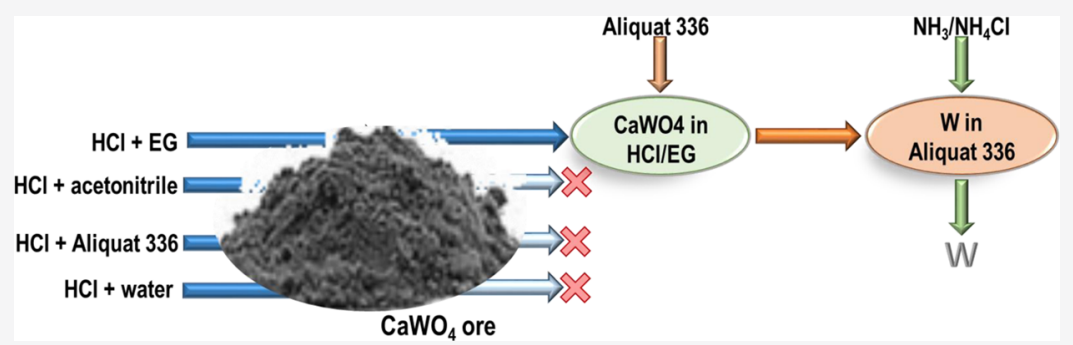

ABSTRACT: The industrial state-of-the-art processes to extract tungsten from scheelite $\left(\mathrm{CaWO}_{4}\right)$ require high pressures and temperatures. These flowsheets consume a large excess of chemicals (which are very hard to recycle) and generate up to 25 tons of high-salinity wastewater per ton of ammonium paratungstate product. In this work, a more sustainable conceptual flowsheet for the recovery of tungsten from high-grade $(55.0 \mathrm{wt} \% \mathrm{~W})$ and medium-grade $(3.3 \mathrm{wt} \% \mathrm{~W})$ scheelite ores was developed at the lab scale. Leaching of $\mathrm{CaWO}_{4}$ was tested in solutions of $37.0 \mathrm{wt} \%$ aqueous $\mathrm{HCl}$ in organic solvents (ethylene glycol, poly(ethylene glycol) 200, acetonitrile) and ionic liquids (Aliquat 336). The tungstate $\left(\mathrm{H}_{x} \mathrm{~W}_{y} \mathrm{O}_{z}{ }^{n-}\right)$ generated by the reaction between CaWO $\mathrm{C}_{4}$ and $\mathrm{HCl}$ was only solubilized in the ethylene glycol system with an appropriate amount of 37.0 wt \% aqueous $\mathrm{HCl}$, whereas in all other solvents, it either precipitated or $\mathrm{CaWO}_{4}$ did not dissolve. After the dissolution of tungsten, nonaqueous solvent extraction was used to separate tungsten from calcium, by means of a solvent consisting of 20 vol \% Aliquat 336 in the aliphatic diluent GS190 with 10 vol \% 1-decanol as a modifier. Scrubbing with water removed the co-extracted iron. Finally, tungsten was recovered as ammonium tungstate $\left(\mathrm{NH}_{4}\right)_{2} \mathrm{WO}_{4}$, the precursor of ammonium paratungstate, by stripping in a mixture of aqueous ammonia and ammonium chloride. Paratungstate is the most common intermediate for the production of tungsten oxide or tungsten metal. One drawback that needs to be adequately addressed, prior to further upscaling of this conceptual flowsheet, is the potential formation of trace levels of 2-chloroethanol in the leaching stage. It is hypothesized that this problem can be circumvented by further optimizing process conditions to enhance the mass transfer and reduce the reaction time, such as better mixing of the solid and the lixiviant.

\section{INTRODUCTION}

Tungsten is a critical commodity mainly employed as tungsten carbide (WC) which, in turn, is used in metalwork tools, a very large base application for sectors such as construction, metalworking, mining, and oil and gas drilling. ${ }^{1}$ In addition, the economic importance of tungsten is increasing, due to its very high substitution index and its application in crucial, fastdeveloping technologies such as robotics, drones, and $3 \mathrm{D}$ printing. ${ }^{2,3}$ In 2019, the U.S. had an import reliance on tungsten above $50 \%$ and the supply of secondary sources, mostly via recycling of $\mathrm{WC}$, would not meet the demand for this metal. ${ }^{1}$ To increase the resilience of the tungsten supply chain, the U.S. Geological Survey has recently launched the first study of domestic tungsten resources and mineral potential in over 20 years. ${ }^{4}$ Appreciable amounts of tungsten resources were found to be economically suitable for exploitation, although the increasingly low grade of the primary sources necessitates preconcentration steps and renders the primary extraction increasingly complex. ${ }^{5}$ In this work, we developed a process to efficiently recover tungsten from scheelite, $\mathrm{CaWO}_{4}$, present in high-grade (55 wt \% W) and medium-grade (3.3 wt \%) ores, relevant to the exploitation of primary tungsten sources.

Scheelite and wolframite, $(\mathrm{Fe}, \mathrm{Mn}) \mathrm{WO}_{4}$, are the two main tungsten ores, with scheelite being the easiest to dissolve. The core step in the flowsheet of the conventional industrial processing of scheelite is digestion with $\mathrm{NaOH}$ or $\mathrm{Na}_{2} \mathrm{CO}_{3}$ to convert $\mathrm{CaWO}_{4}$ into $\mathrm{Na}_{2} \mathrm{WO}_{4}$, followed by the removal of impurities and acidification of the $\mathrm{Na}_{2} \mathrm{WO}_{4}$ solution ( $\mathrm{pH} 2-$ 3). Tungsten is then recovered via solvent extraction with protonated trioctylamine (or its commercial mixture Alamine

Received: October 4, 2021

Revised: November 29, 2021

Accepted: December 1, 2021

Published: December 22, 2021

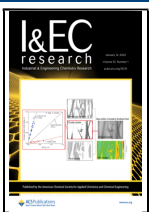


336) and stripped with an aqueous ammonia solution to obtain ammonium paratungstate (APT), $\left(\mathrm{NH}_{4}\right)_{10}\left(\mathrm{H}_{2} \mathrm{~W}_{12} \mathrm{O}_{42}\right) \cdot 4 \mathrm{H}_{2} \mathrm{O}$. The latter salt is crystallized and calcined to tungsten(VI) oxide and, finally, reduced by hydrogen gas to metallic tungsten powder. ${ }^{6}$ The current industrial process was established more than 60 years ago, and at the time, it significantly increased tungsten recovery yields, while optimizing the energy efficiency and labor costs. ${ }^{6}$ Nevertheless, it still has several drawbacks, including the need for digestion in $\mathrm{NaOH}$ or $\mathrm{Na}_{2} \mathrm{CO}_{3}$. Although being necessary to obtain a water-soluble form of tungsten, this step implies working in an autoclave at pressures between 1.2 and $2.6 \mathrm{~atm}$, temperatures around $200{ }^{\circ} \mathrm{C}$, and the large excesses of reagents, which are not or hardly recycled and generate at least 25 tons of highsalinity acidic wastewater per ton of APT product in the solvent extraction step. ${ }^{7,8}$

In the literature, different approaches to avoid the formation of $\mathrm{Na}_{2} \mathrm{WO}_{4}$ and high-salinity wastewater have been suggested. A first series of alternatives were the processes using $\mathrm{H}_{3} \mathrm{PO}_{4}$ as a chelating agent to recover tungsten as a heteropolytungstate $\left(\mathrm{NH}_{4}\right)_{3} \mathrm{PW}_{12} \mathrm{O}_{40} \cdot 9 \mathrm{H}_{2} \mathrm{O}$, which also include attempts to recycle the acidic solutions. ${ }^{9-13}$ The use of $\mathrm{H}_{2} \mathrm{SO}_{4}$ or of mixtures of $\mathrm{H}_{2} \mathrm{SO}_{4} / \mathrm{H}_{3} \mathrm{PO}_{4}$ to dissolve scheelite was also investigated, obtaining soluble $\mathrm{Na}_{2} \mathrm{WO}_{4}$ and insoluble $\mathrm{CaSO}_{4} \cdot{ }^{14-16}$ A more innovative technology was developed by $\mathrm{Li}$ and co-workers, based on roasting and $\left(\mathrm{NH}_{4}\right)_{2} \mathrm{CO}_{3}$ leaching, with the main advantages being the recyclability of the chemicals used in the process and the lack of discharged wastewater. ${ }^{17,18}$ Recently, a process was developed, which entails $\mathrm{H}_{2} \mathrm{SO}_{4}$ conversion of $\mathrm{CaWO}_{4}$ to $\mathrm{H}_{2} \mathrm{WO}_{4}$ followed by $\left(\mathrm{NH}_{4}\right)_{2} \mathrm{CO}_{3}$ leaching. ${ }^{19,20}$ It is based on a patent comprising $\mathrm{CaWO}_{4}$ leaching in $\mathrm{H}_{2} \mathrm{SO}_{4}$ (followed by leaching and separation of the formed $\mathrm{H}_{2} \mathrm{WO}_{4}$ in ethylene glycol). ${ }^{21}$ APT was obtained without the formation of $\mathrm{Na}_{2} \mathrm{WO}_{4}$, and the reagents were recycled. Although this process is very promising, it still includes the formation of solid intermediates such as $\mathrm{H}_{2} \mathrm{WO}_{4}$ and $\mathrm{CaSO}_{4}$ with consecutive dissolution-filtration-dissolution steps. More innovative resin-enhanced acid leaching of $\mathrm{CaWO}_{4}$ from high-grade ores has also been developed, but the separation and purification of the formed $\mathrm{H}_{2} \mathrm{WO}_{4}$ and the cost-effectiveness of the process were not evaluated. ${ }^{22}$ Optimization of tungsten recovery from $\mathrm{CaWO}_{4}$ in alkaline media has also been extensively investigated: those processes are usually based on leaching in $\mathrm{NaOH}$ solutions to convert the tungsten into the water-soluble $\mathrm{Na}_{2} \mathrm{WO}_{4}$, although large excess of $\mathrm{NaOH}$, temperatures above $100{ }^{\circ} \mathrm{C}$, and high pressure are required for recovery efficiency $\geq 90 \% .{ }^{23-28}$ In fact, tungsten compounds cannot be leached in aqueous $\mathrm{HCl}$ since tungsten precipitates as $\mathrm{H}_{2} \mathrm{WO}_{4}$ on the particle interfaces, limiting the dissolution of the particles themselves. Martins and co-workers studied the leaching of scheelite in aqueous $\mathrm{HCl}$ solutions at a controlled $\mathrm{pH}$, concluding that it can be possible with a large excess of leaching reagent. ${ }^{29,30}$ Other factors that can facilitate the process are: (i) a smaller particle size, to enhance the mass transfer; (ii) a heated ball mill, to destroy the $\mathrm{H}_{2} \mathrm{WO}_{4}$ layer; (iii) the use of complexing agents, such as $\mathrm{H}_{3} \mathrm{PO}_{4}$ or organic acids (tartaric acid or citric acid); and (iv) the use of alcoholic solvents to solubilize the $\mathrm{H}_{2} \mathrm{WO}_{4}$. The use of a heated ball mill is difficult to scale up and organic acids are too expensive. By contrast, the use of $\mathrm{HCl}$-alcohol mixtures, in particular of $\mathrm{HCl}$-ethanol-water, to recover tungsten as $\mathrm{H}_{2} \mathrm{WO}_{4}$ was patented in $1966^{31}$ and was then further studied by Girgin and co-workers. ${ }^{32,33}$ Partial or total substitution of water by alcohols suppresses hydrolysis and allows us to control the reaction chemically rather than by diffusion. Unfortunately, all of these processes lead to the formation of solid $\mathrm{H}_{2} \mathrm{WO}_{4}$, which limits the dissolution of the particles themselves.

In the present paper, we demonstrate how to successfully circumvent the formation of solid reaction products in the leachate by dissolving scheelite, $\mathrm{CaWO}_{4}$, in $37.0 \mathrm{wt} \%$ aqueous $\mathrm{HCl}-$ ethylene glycol mixtures and purifying the tungsten by nonaqueous solvent extraction (NASX).

\section{EXPERIMENTAL SECTION}

Chemicals. $\mathrm{CaWO}_{4}$ (98.0\%) was supplied by Thermo Fisher GmbH (Kandel, Germany). Two grades of scheelite ores, i.e., a high-grade ore with a tungsten content of about 55 wt \% (55-W) and a medium-grade preconcentrate containing about 3.3 wt \% tungsten (3-W), were kindly provided by Saloro S.L. (Barruecopardo, Spain), and when required pretreated by gravimetric separation (ULiège, Belgium). Aqueous hydrochloric acid $(\mathrm{HCl}, 37.0 \mathrm{wt} \%)$, ultrapure $\mathrm{NaCl}$ for volumetric titration (99.99+\%), and ammonia solution $\left(\mathrm{NH}_{3}, 25.0\right.$ wt \% solution in water) were ordered from VWR Chemicals (Heverlee, Belgium); boric acid $\left(\mathrm{H}_{3} \mathrm{BO}_{3}, \geq 99.5 \%\right)$ was purchased from VWR International (Heverlee, Belgium). Ethylene glycol (99.0+\%), 1-decanol $(98.0+\%)$, and Aliquat $336 \mathrm{TG}$ were purchased from Acros Organics (Geel, Belgium); ICP metal standards (all $1000 \mathrm{mg}$ $\mathrm{L}^{-1}$ ), acetonitrile (a.r.), tri- $n$-butylphosphate (TBP, $99.0+\%$ ), $\mathrm{CaCl}_{2}$ (99.0+\%), silver nitrate titrant $\left(\mathrm{AgNO}_{3}, 0.1 \mathrm{~mol} \mathrm{~L}{ }^{-1}\right)$, and nitric acid $\left(\mathrm{HNO}_{3}, 65.0 \mathrm{wt} \%\right)$ were supplied by ChemLab (Zedelgem, Belgium). Hydrofluoric acid (HF, 48.0 wt \%) and poly(ethylene glycol) 200 (PEG-200, a.r.) were purchased from Merck (Steinheim, Belgium) and ICP standard uranium $10 \mathrm{mg} \mathrm{L}^{-1}$ from Merck KGaA (Darmstadt, Germany). Trioctylamine (TOA, 99.0+\%) and deuterated dimethyl sulfoxide (DMSO- $d_{6} 99.9 \%$ atom D for NMR) were purchased from Sigma-Aldrich (Diegem, Belgium). Cyanex 923, a mixture of four trialkylphosphine oxides, was purchased from Cytec (Vlaardingen, The Netherlands). ShellSol A150, ShellSol G70, ShellSol D70, Shell GTL Solvent GS190, and Shell GTL Solvent GS250 were supplied by Shell Chemicals Europe BV (Rotterdam, The Netherlands). Ultrapure water deionized to a resistivity of $18.2 \mathrm{M} \Omega \cdot \mathrm{cm}$ was produced using a Millipore Reference+ ultrapure water system. All chemicals were used as received without any further purification.

Lixiviant Preparation and Stability. The lixiviants were prepared by dilution of $37.0 \mathrm{wt} \%$ aqueous $\mathrm{HCl}$ in water, ethylene glycol, poly(ethylene glycol) 200 (PEG-200), and acetonitrile or by extraction of $37.0 \mathrm{wt} \%$ aqueous $\mathrm{HCl}$ in Aliquat 336. About $0.1 \mathrm{~g}$ of $\mathrm{CaWO}_{4}$ in $2 \mathrm{~mL}$ of each solution was stirred at $60{ }^{\circ} \mathrm{C}$ and $1000 \mathrm{rpm}$ for up to $4 \mathrm{~h}$ until a full dissolution was observed or yellow, solid $\mathrm{H}_{2} \mathrm{WO}_{4}$ was formed. The stability of the solutions under storage and process conditions was monitored via ${ }^{1} \mathrm{H}$ NMR spectroscopy on a Bruker Avance II $+600 \mathrm{MHz}$ spectrometer (solvent DMSO- $d_{6}$ ) and via gas chromatography/mass spectrometry (GC/MS) measurements (PerkinElmer Autosystem XL/Turbomass Kolom equipped with a PerkinElmer column of $60 \mathrm{~cm}$ length and $0.25 \mathrm{~mm}$ diameter, coating Perkin 5MS and film thickness of $1 \mu \mathrm{m}$ ). Other operational parameters were: injection volume $=1 \mu \mathrm{L}$; oven temperature $=45-230^{\circ} \mathrm{C}$; injection temperature $=220{ }^{\circ} \mathrm{C}$; source temperature $=200{ }^{\circ} \mathrm{C}$; helium pressure on

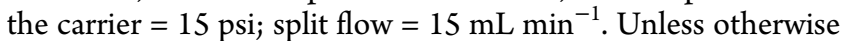
stated, the samples studied by ${ }^{1} \mathrm{H}$ NMR and GC/MS consisted 
of $2 \mathrm{~mol} \mathrm{~L}^{-1} 37.0 \mathrm{wt} \%$ aqueous $\mathrm{HCl}$ in ethylene glycol. They were stirred for 8 and $24 \mathrm{~h}$ at 40 and $60{ }^{\circ} \mathrm{C}$. The samples were diluted 5 times in ethanol and 20 times in DMSO prior to the GC/MS and ${ }^{1} \mathrm{H}$ NMR analysis, respectively.

Leaching Tests. The lixiviants, in which full dissolution of $\mathrm{CaWO}_{4}$ was observed, were further investigated for the leaching of the high-grade or medium-grade pre-concentrated of scheelite ores, referred to as $55-\mathrm{W}$ and $3-\mathrm{W}$, respectively. The 55-W and 3-W solids were characterized via analysis with ICP-OES (Optima 8300, PerkinElmer), after prior digestion using a microwave digester (Mars 6, CEM, equipped with EasyPrep iWave vessels) with $4.0 \mathrm{~mL}$ of $65 \mathrm{wt} \% \mathrm{HNO}_{3}, 5.0$ $\mathrm{mL}$ of 37 wt $\% \mathrm{HCl}$, and $3.0 \mathrm{~mL}$ of 48 wt \% $\mathrm{HF}$, followed by HF neutralization with $6.0 \mathrm{~mL}$ of 4 wt $\% \mathrm{H}_{3} \mathrm{BO}_{3}$ per $\mathrm{mL}$ of $\mathrm{HF}$. Calibration standards for the ICP-OES analysis ranged from 0.1 to $5.0 \mathrm{mg} \mathrm{L}^{-1}$. Germanium and indium were used as internal standards for elements with I and II ionization state, respectively. The leaching tests were carried out on the solids (55-W or 3-W) at a liquid-to-solid (L-S) ratio of $20 \mathrm{~mL} \mathrm{~g}$. The samples were stirred in aluminum heating blocks at 1000 $\mathrm{rpm}$ at a temperature of $40,60,80$, or $100{ }^{\circ} \mathrm{C}$ for $1-16 \mathrm{~h}$. The blank of the lixiviant-with no addition of solid-was also stirred under the same conditions and was prepared for the ${ }^{1} \mathrm{H}$ NMR or GC/MS analysis (vide supra). At the end of the tests, the leachates were filtered and properly diluted for elemental analysis with ICP-OES (vide supra). All tests were performed in triplicate. The percentage of metal extraction in the leaching $\left(\% E_{\mathrm{L}}\right)$ was calculated as

$$
\% E_{\mathrm{L}}=\frac{n_{\mathrm{M}, 1}}{n_{\mathrm{M}, \max }} \times 100
$$

where $n_{\mathrm{M}, 1}$ denotes the number of moles of the metal in the leachate and $n_{\mathrm{M} \text {,max }}$ represents the maximum number of moles of the metal after complete digestion of the solid.

Nonaqueous Solvent Extraction, Scrubbing, and Stripping Tests. Nonaqueous solvent extraction (NASX) of metals was performed by shaking a certain volume of two immiscible organic phases in $4.0 \mathrm{~mL}$ vials, using a Nemus Life Thermo Shaker TMS-200 (Nemus LIFE AB, Lund, Sweden). The more polar feed (MP) contained tungsten, iron, calcium, and aluminum in $2 \mathrm{~mol} \mathrm{~L}^{-1} \mathrm{HCl}$ and $2 \mathrm{~mol} \mathrm{~L}^{-1} \mathrm{CaCl}_{2}$ in ethylene glycol. The less polar organic phase (LP) was composed of an extractant, a diluent, and a phase modifier. Different extractants (i.e., Cyanex 923, tri- $n$-butylphosphate (TBP), Aliquat 336 chloride, and tri- $n$-octyl amine (TOA)); aliphatic and aromatic diluents (respectively, ShellSol G70, ShellSol D70, Shell GTL Solvent GS190, Shell GTL Solvent GS250, $n$-dodecane, and ShellSol A150; xylene, $p$-cymene, and toluene); and salting-out agent concentration in the MP (0-2 mol L ${ }^{-1} \mathrm{CaCl}_{2}$ ) were screened to optimize the NASX of tungsten. Unless stated otherwise, the experimental conditions were kept constant: $\mathrm{MP} / \mathrm{LP}$ ratio $=1 / 1$; temperature, $T=25$ ${ }^{\circ} \mathrm{C}$, mixing speed, $r=2000 \mathrm{rpm}$; mixing time, $t_{\text {mix }}=60 \mathrm{~min}$. The McCabe-Thiele diagrams for $\mathrm{W}$ extraction were constructed using different MP/LP phase ratios from $1 / 5$ to $5 / 1$ to determine the theoretical number of countercurrent stages. After extraction, the phase disengagement was accelerated by centrifuging at $5000 \mathrm{rpm}$ for $5 \mathrm{~min}$ with a Heraeus Labofuge 200 centrifuge (Thermo Fisher Scientific, Asse, Belgium). The MP raffinate phase was then diluted in a mixture of 2 vol $\% \mathrm{HNO}_{3}$ and $0.5 \mathrm{vol} \% \mathrm{HBF}_{4}$ as background solution to determine the metal content with ICP-OES. The concentration of the metals in the LP was calculated by mass balance. The percentage extraction of metals $\left(\% E_{\mathrm{SX}}\right)$ was calculated as

$$
\% E_{\mathrm{SX}}=\frac{n_{\mathrm{M}, \mathrm{LP}}}{n_{\mathrm{M}, \mathrm{MP}}} \times 100
$$

with $n_{\mathrm{M}, \mathrm{LP}}$ and $n_{\mathrm{M}, \mathrm{MP}}$ denoting the number of moles per metal in the LP and MP phases, respectively.

In a similar way to NASX, the scrubbing tests were performed by equilibrating the loaded LP phases with different scrubbing agent solutions (i.e., water, $0.5 \mathrm{~mol} \mathrm{~L}^{-1} \mathrm{HCl}$, and $0.25 \mathrm{~mol} \mathrm{~L}^{-1} \mathrm{H}_{2} \mathrm{SO}_{4}$ ) at a phase ratio of unity. The percentage scrubbing of metals (\%SB) was calculated as

$$
\% \mathrm{SB}=\frac{n_{\mathrm{M}, \mathrm{aq}}}{n_{\mathrm{M}, \mathrm{org}}} \times 100
$$

The selective stripping of tungsten from the scrubbed LP solvents was investigated using different stripping agent solutions of $\mathrm{NH}_{3}, \mathrm{NH}_{4} \mathrm{Cl}$, or a mixture of $\mathrm{NH}_{3}$ and $\mathrm{NH}_{4} \mathrm{Cl}$ at a certain $\mathrm{O} / \mathrm{A}$ phase ratio. The concentration of the stripping agents was varied from 0.0 to $2.5 \mathrm{~mol} \mathrm{~L}^{-1}$. The percentage stripping of metals (\%ST) was calculated as

$$
\% \mathrm{ST}=\frac{n_{\mathrm{M}, \mathrm{aq}}}{n_{\mathrm{M}, \mathrm{org}}} \times 100
$$

with $n_{\mathrm{M} \text {,aq }}$ and $n_{\mathrm{M} \text {,org }}$ denoting the number of moles per metal in the aqueous and organic phases, respectively. An overview of the parameters investigated in each process unit is displayed in Table 1.

Table 1. Overview of the Parameters Investigated for the Solvometallurgical Recovery of Tungsten from Scheelite

\begin{tabular}{|ll}
\multicolumn{1}{c}{ process unit } & \multicolumn{1}{c}{ parameter } \\
\hline solvent preparation & stability over time \\
& stability over temperature \\
& $\mathrm{HCl}$ diluent \\
solvoleaching & temperature \\
& time \\
nonaqueous solvent extraction & extractant \\
& extractant concentration \\
& diluent and phase modifier \\
& O/A ratio \\
number of stages \\
stripping & scrubbing agent \\
& stripping agent \\
& stripping agent concentration \\
& temperature \\
& number of stages
\end{tabular}

\section{RESULTS AND DISCUSSION}

Dissolution of $\mathrm{CaWO}_{4}$. In conventional hydrometallurgy, the dissolution of scheelite $\left(\mathrm{CaWO}_{4}\right)$ in $37.0 \mathrm{wt} \%$ aqueous $\mathrm{HCl},\left(\mathrm{HCl}_{\mathrm{aq}}\right)$, solutions would lead to the formation of solid tungstic acid $\left(\mathrm{H}_{2} \mathrm{WO}_{4}\right)$, which deposits on the solid particles and passivates the particles for further leaching

$$
\left(\mathrm{CaWO}_{4}\right)_{\mathrm{s}}+\mathrm{HCl}_{\mathrm{aq}} \stackrel{\mathrm{H}_{2} \mathrm{O}}{\longrightarrow}\left(\mathrm{H}_{2} \mathrm{WO}_{4}\right)_{\mathrm{s}}+\mathrm{CaCl}_{2, \mathrm{aq}}
$$

Organic solutions (with less than 12 vol.\% water) of hydrogen chloride in alcohols at atmospheric or superatmospheric 
pressure have been proven to dissolve $\mathrm{CaWO}_{4}$ and to solvate $\mathrm{H}_{2} \mathrm{WO}_{4}{ }^{31-33}$ We have screened solvometallurgical solutions of $2 \mathrm{~mol} \mathrm{~L}^{-1} \mathrm{HCl}_{\mathrm{aq}}$ in ethylene glycol, poly(ethylene glycol) 200 (PEG-200), acetonitrile, and Aliquat 336 for the dissolution of synthetic $\mathrm{CaWO}_{4}$ at $80{ }^{\circ} \mathrm{C}$. Those solvents, both polar and apolar, were able to dilute the $\mathrm{HCl}$ and were stable at the tested reaction temperatures. The total water content in these solvometallurgical solutions was about $10.5 \mathrm{vol} \%$. No tungsten precipitation occurred in ethylene glycol or in PEG-200, although it did happen in the acetonitrile and Aliquat 336 solutions, even at a low water content (see Figure S1). Similarly, $\mathrm{H}_{2} \mathrm{WO}_{4}$ also precipitated from ethylene glycol and PEG-200 solutions as the $\mathrm{HCl}_{\mathrm{aq}}$ content was increased from 3 to $6 \mathrm{~mol} \mathrm{~L}^{-1}$ (Figure S2) because of the higher water content introduced with $\mathrm{HCl}_{\mathrm{aq}}$. Dissolution of $\mathrm{CaWO}_{4}$ in $2 \mathrm{~mol} \mathrm{~L}^{-1}$ of $\mathrm{HCl}_{\mathrm{aq}}$ in water was studied for comparison and the formation of yellow, solid $\mathrm{H}_{2} \mathrm{WO}_{4}$ was observed as well (Figures $\mathrm{S} 1$ and S2). The screening tests revealed that at $2 \mathrm{~mol} \mathrm{~L}^{-1} \mathrm{HCl}_{\mathrm{aq}}$ (water content of about $10.5 \mathrm{vol} \%$ ), ethylene glycol and PEG200 stabilize the dissolved tungsten in solution. However, the PEG-200 solution was discarded because of its higher viscosity, which would affect the further liquid-liquid extraction steps.

Characterization and Solvoleaching of Tungsten Ores. Two $\mathrm{CaWO}_{4}$ ore samples $55-\mathrm{W}$ and $3-\mathrm{W}$ were digested by mineral acids in a microwave reactor, and the elemental composition was determined via ICP-OES analysis (Table 2).

Table 2. Elemental Composition of the Solid Samples 55-W (55.0 wt \% W) and 3-W (3.5 wt \% W) determined by ICPOES

\begin{tabular}{|ccccc|}
\hline wt \% metal & $55-\mathrm{W}$ & $\mathrm{RSD} \%$ & $3-\mathrm{W}$ & $\mathrm{RSD} \%$ \\
$\mathrm{~W}$ & 54.9 & 1.83 & 3.3 & 0.50 \\
$\mathrm{Al}$ & n.d. & 0.84 & 4.8 & 1.87 \\
$\mathrm{As}$ & 1.9 & 1.32 & 1.5 & 4.09 \\
$\mathrm{Ca}$ & 16.8 & 0.46 & 2.1 & 0.98 \\
$\mathrm{Fe}$ & 4.8 & 0.84 & 4.7 & 1.47 \\
$\mathrm{~K}$ & n.d. & & 2.8 & 1.79 \\
$\mathrm{Mn}$ & 0.4 & 0.19 & 0.2 & 2.72 \\
$\mathrm{Na}$ & n.d. & & 1.3 & 2.21 \\
$\mathrm{P}$ & 1.9 & 0.08 & 0.6 & 2.77 \\
$\mathrm{~S}$ & n.d. & & 2.6 & 3.00 \\
$\mathrm{Ti}$ & 1.4 & 0.04 & 0.2 & 2.36 \\
\hline
\end{tabular}

$\mathrm{CaWO}_{4}$ dissolved completely in $2 \mathrm{~mol} \mathrm{~L}^{-1} \mathrm{HCl}_{\mathrm{aq}}$-EG within $1 \mathrm{~h}$ at $60{ }^{\circ} \mathrm{C}$ and in excess of $3 \mathrm{~h}$ at $40{ }^{\circ} \mathrm{C}$. Given this considerable difference in dissolution time, the leaching of 55$\mathrm{W}$ and $3-\mathrm{W}$ solids was carried out only at $60{ }^{\circ} \mathrm{C}$. An aliquot of $2.0 \mathrm{~mL}$ of $2 \mathrm{~mol} \mathrm{~L}^{-1} \mathrm{HCl}_{\mathrm{aq}}$-EG was used to leach, in triplicate, $0.1 \mathrm{~g}$ of $55-\mathrm{W}$ or $3-\mathrm{W}$ solid at $60{ }^{\circ} \mathrm{C}$ and $1000 \mathrm{rpm}$ for $1,4,6$, and $8 \mathrm{~h}$. The leaching efficiency, $\% E_{\mathrm{L}}$, and the leachate composition, $c_{\mathrm{M}}\left(\mathrm{g} \mathrm{L}^{-1}\right)$, are depicted in Figures 1 and 2 for, respectively, 55-W and 3-W. After $8 \mathrm{~h}, \geq 95.0 \%$ tungsten from the 3-W sample was leached with a final concentration of $1.6 \mathrm{~g}$ $\mathrm{L}^{-1}$, whereas, given the different composition (cf. Table 2) of the 55-W leachate, the latter had a higher tungsten content (18.0 $\mathrm{g} \mathrm{L} \mathrm{L}^{-1}$ ) although the leaching efficiency was lower $(67.0 \%)$. In both cases, the main impurity was calcium with contents of ca. 1.1 and $5.8 \mathrm{~g} \mathrm{~L}^{-1}$ in the $3-\mathrm{W}$ and $55-\mathrm{W}$ leachates, respectively. The former also contained iron(III) at a significant concentration $\left(0.7 \mathrm{~g} \mathrm{~L}^{-1}\right)$. The calcium dissolved was higher than that corresponding solely to the $\mathrm{CaWO}_{4}$
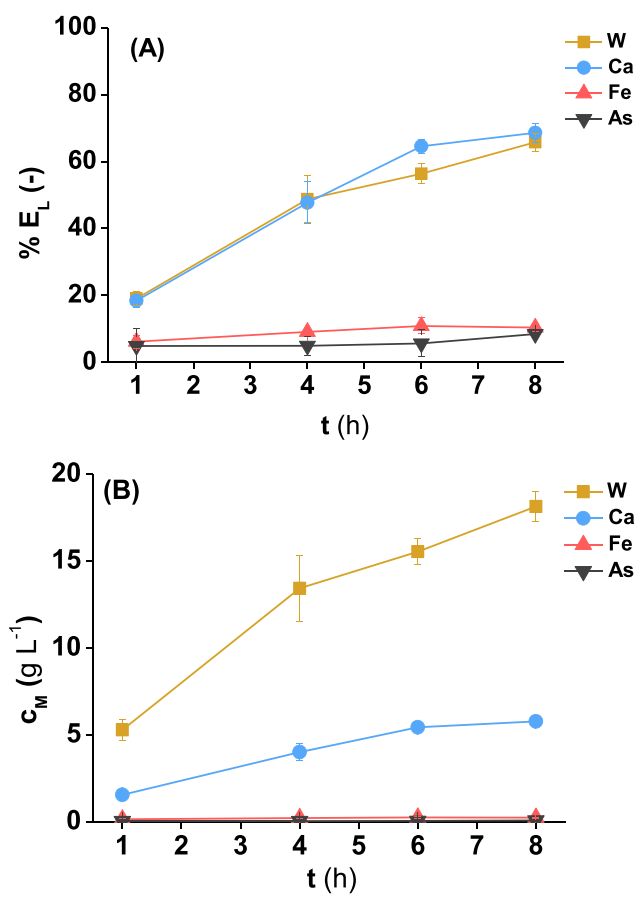

Figure 1. (A) Leaching efficiency, $\% E_{\mathrm{L}}$, and (B) metal concentration, $c_{\mathrm{M}}\left(\mathrm{g} \mathrm{L}^{-1}\right)$, as a function of leaching time, $t(\mathrm{~h})$, for the 55-W sample. Working conditions: lixiviant: $2 \mathrm{~mol} \mathrm{~L} \mathrm{~L}^{-1} \mathrm{HCl}_{\mathrm{aq}} / \mathrm{EG}$; $\mathrm{L}-\mathrm{S}$ ratio $=20$ $\mathrm{mL} \mathrm{g}{ }^{-1}, T=60{ }^{\circ} \mathrm{C}$, and $r=1000 \mathrm{rpm}$. See Table 2 for $55-\mathrm{W}$ composition.
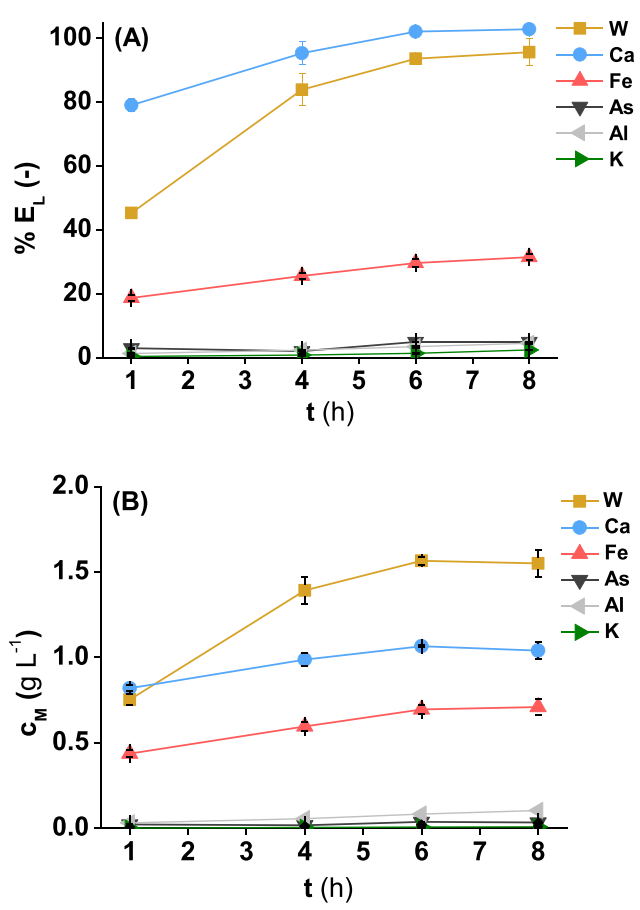

Figure 2. (A) Leaching efficiency, $\% E_{\mathrm{L}}$, and (B) metal concentration, $c_{\mathrm{M}}\left(\mathrm{g} \mathrm{L}^{-1}\right)$, as a function of the leaching time, $t(\mathrm{~h})$, for the $3-\mathrm{W}$ sample. Working conditions: lixiviant: $2 \mathrm{~mol} \mathrm{~L}^{-} \mathrm{HCl}_{\mathrm{aq}} / \mathrm{EG}$; $\mathrm{L}-\mathrm{S}$ ratio $=20 \mathrm{~mL} \mathrm{~g}^{-1}, T=60{ }^{\circ} \mathrm{C}$, and $r=1000 \mathrm{rpm}$. See Table 2 for 3-W composition.

dissolution since calcium is also present, in both ore samples, in other minerals such as apatite and calcite.

The shelf-life stability of the $2.0 \mathrm{~mol} \mathrm{~L}-1 \mathrm{HCl}_{\mathrm{aq}} / \mathrm{EG}$ solution stored in the fridge at $2.0{ }^{\circ} \mathrm{C}$ was monitored via ${ }^{1} \mathrm{H}$ NMR 
analysis with a high-field $(600 \mathrm{MHz})$ spectrometer on the asprepared solution and after 1, 2, and 4 weeks: no decomposition products were detected, and fridge storage was considered safe (Figures S3-S6). However, a trace-level formation of 2-chloroethanol or dichloroethane could happen, following eqs 6 and 7; this was investigated on blanks of waterlean $\mathrm{HCl}_{\mathrm{aq}}$ in ethylene glycol, stirred for $8 \mathrm{~h}$ at 40,60, and 80 ${ }^{\circ} \mathrm{C}$. The $600 \mathrm{MHz}{ }^{1} \mathrm{H} \mathrm{NMR}$ spectra showed that 2chloroethanol only formed at $80{ }^{\circ} \mathrm{C}$ (at about $\delta=3.55,(\mathrm{~m}$, $\left.\mathrm{CH}_{2}\right)$ ), whereas dichloroethane did not form at any temperature (Figures S7-S9).

$$
\begin{aligned}
& \mathrm{HOCH}_{2} \mathrm{CH}_{2} \mathrm{OH}+\mathrm{HCl} \rightarrow \mathrm{HOCH}_{2} \mathrm{CH}_{2} \mathrm{Cl}+\mathrm{H}_{2} \mathrm{O} \\
& \mathrm{HOCH}_{2} \mathrm{CH}_{2} \mathrm{Cl}+\mathrm{HCl} \rightarrow \mathrm{ClCH}_{2} \mathrm{CH}_{2} \mathrm{Cl}+\mathrm{H}_{2} \mathrm{O}
\end{aligned}
$$

Additionally, blanks of $2 \mathrm{~mol} \mathrm{~L}^{-1} \mathrm{HCl}_{\mathrm{aq}}$ in ethylene glycol were stirred for 8 and $24 \mathrm{~h}$ at 40 and $60{ }^{\circ} \mathrm{C}$ and analyzed by GC/ MS. Dichloroethane was not detected, whereas traces of 2chloroethanol were detected (see Table S1). The disagreement between the results from ${ }^{1} \mathrm{H}$ NMR and GC/MS analyses is explained by the higher detection limit $(\sim 5 \%)$ of the ${ }^{1} \mathrm{H}$ NMR. For further study, it can be therefore recommended to consider different process conditions to prevent the formation of undesired products.

Nonaqueous Solvent Extraction and Purification of Tungsten. Further processing steps were necessary to separate the tungsten from metal impurities in the leachate. NASX was used for the purification of the tungsten. Screening tests were carried out on a synthetic solution, which was prepared by adding a known amount of $\mathrm{CaWO}_{4}, \mathrm{CaCl}_{2}, \mathrm{AlCl}_{3}$, and $\mathrm{FeCl}_{3}$ in $2 \mathrm{~mol} \mathrm{~L}^{-1} \mathrm{HCl}_{\mathrm{aq}}$ in ethylene glycol. Solvating (neutral) extractants (i.e., TBP and Cyanex 923) and basic extractants (i.e., TOA and Aliquat 336) were diluted in Shell GTL Solvent GS190, and with 10 vol \% 1-decanol as a phase modifier, and they were used as the less polar (LP) phase. The effect of adding $\mathrm{CaCl}_{2}$ to the MP phase as a salting-out agent was investigated as well (Figure 3 ).

Good phase separation was achieved for all of the solvents tested as the LP phase due to the presence of the phase modifier, 1-decanol. Appreciable tungsten extraction, $\% E_{\mathrm{SX}}$ $\geq 60.0$, was achieved only in 20 vol.\% Aliquat 336 or Cyanex 923 both with $2 \mathrm{~mol} \mathrm{~L}^{-1} \mathrm{CaCl}_{2}$. The majority of iron(III) was co-extracted by all extractants except TBP. Other impurities like $\mathrm{Ca}(\mathrm{II})$ and $\mathrm{Al}(\mathrm{III})$ were poorly extracted, yielding a first mechanism of process selectivity. Moreover, the addition of $\mathrm{CaCl}_{2}$ enhanced the extraction of iron(III) even by TBP and, most importantly, the extraction of tungsten by all LP solvents. Scrubbing of iron(III) was a critical step for tungsten purification. Table 3 shows the percentage scrubbing of iron(III) using individual scrubbing agent solutions (i.e., water, $0.5 \mathrm{~mol} \mathrm{~L}^{-1} \mathrm{HCl}$ and $\left.0.25 \mathrm{~mol} \mathrm{~L}^{-1} \mathrm{H}_{2} \mathrm{SO}_{4}\right)$.

Iron(III) could be efficiently scrubbed with water and with $0.25 \mathrm{~mol} \mathrm{~L}^{-1} \mathrm{H}_{2} \mathrm{SO}_{4}$ in one step from the loaded Aliquat 336 but not from the loaded Cyanex 923. In addition, the quantitative scrubbing of iron(III) from loaded Aliquat 336 is possible using water at $\mathrm{O} / \mathrm{A}=2 / 1$ in a single contact. As for the other impurities, aluminum and calcium were not extracted with Aliquat 336 and were, hence, not scrubbed. In the case of the Cyanex 923 solvent, aluminum was scrubbed with any of the investigated scrubbing agents. However, a poor phase separation was observed during the scrubbing of impurities from loaded Cyanex 923. For further studies, water was preferred over $\mathrm{H}_{2} \mathrm{SO}_{4}$ because it is obviously a more
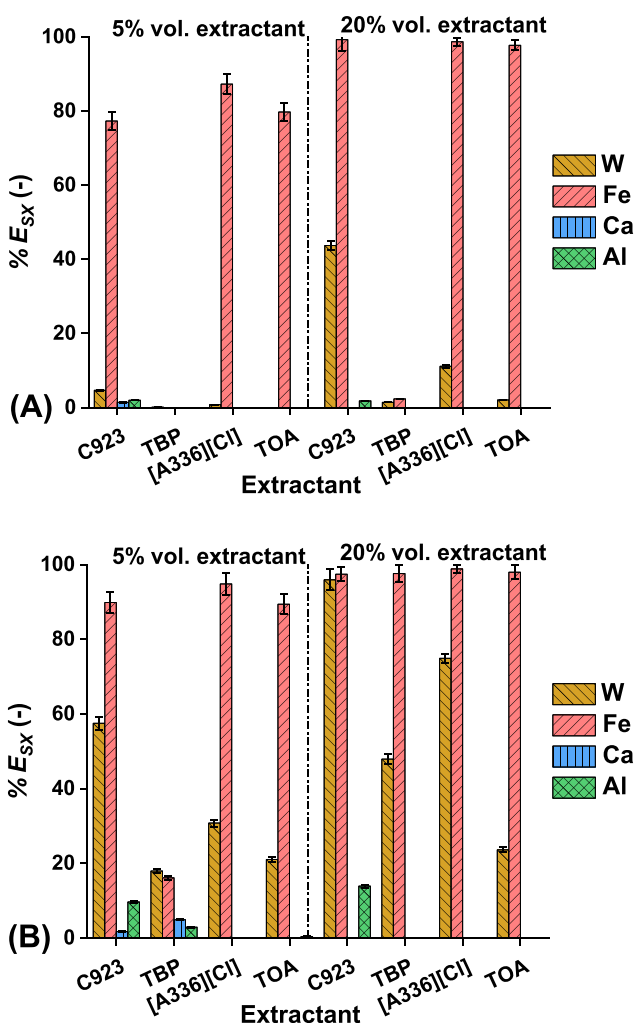

Figure 3. (A) Solvent screening for the NASX of tungsten without addition of $\mathrm{CaCl}_{2}$ and (B) with $\mathrm{CaCl}_{2}$ from a synthetic leachate (1.92 $\mathrm{g} \mathrm{L}^{-1}$ tungsten, $1.40 \mathrm{~g} \mathrm{~L}^{-1}$ iron, $1.11 \mathrm{~g} \mathrm{~L}^{-1}$ calcium, and $1.34 \mathrm{~g} \mathrm{~L}^{-1}$ aluminum in $2 \mathrm{~mol} \mathrm{~L}^{-1} \mathrm{HCl}_{\mathrm{aq}} / \mathrm{EG}$ ). Working conditions: $\left[\mathrm{CaCl}_{2}\right]=2$ mol L ${ }^{-1}$; diluent = Shell GS190; phase modifier = 10 vol \% 1-decanol; $\mathrm{MP} / \mathrm{LP}$ ratio $=1 / 1 ; t=1 \mathrm{~h} ; r=2000 \mathrm{rpm} ; T=$ room temperature.

Table 3. Scrubbing Percentage, \%SB, of Metals in Water, 0.5 mol L ${ }^{-1} \mathrm{HCl}$, and $0.25 \mathrm{~mol} \mathrm{~L}^{-1} \mathrm{H}_{2} \mathrm{SO}_{4}$ from the Loaded Aliquat 336 and Cyanex $923^{a, b}$

\begin{tabular}{ccccc} 
& & \multicolumn{3}{c}{$\% S B$} \\
\cline { 3 - 5 } loaded & & & & \\
organic & elements & water & $0.5 \mathrm{~mol} \mathrm{~L}^{-1} \mathrm{HCl}$ & $\mathrm{H}_{2} \mathrm{SO}_{4}$ \\
Aliquat 336 & $\mathrm{Fe}$ & 82.0 & 41.0 & 90.0 \\
& $\mathrm{Al}$ & $<1$ & $<1$ & $<1$ \\
& $\mathrm{Ca}$ & $<1$ & $<1$ & $<1$ \\
Cyanex 923 & $\mathrm{Fe}$ & 63.0 & 30.0 & 78.0 \\
& $\mathrm{Al}$ & 100.0 & 97.0 & 99.0 \\
& $\mathrm{Ca}$ & $<1$ & $<1$ & $<1$
\end{tabular}

${ }^{a}$ Working conditions: $\mathrm{O} / \mathrm{A}$ ratio $=1 / 1 ; t=1 \mathrm{~h} ; r=2000 \mathrm{rpm} ; t=$ room temperature. ${ }^{b}$ Tungsten scrubbing was $0 \%$ in all cases.

sustainable scrubbing agent. Regarding the tungsten stripping from the loaded solvents, solutions of $1.0 \mathrm{~mol} \mathrm{~L}^{-1} \mathrm{NH}_{3}, 1.0$ mol L$~^{-1} \mathrm{NH}_{4} \mathrm{Cl}$, and mixtures of $1.0 \mathrm{~mol} \mathrm{~L}^{-1} \mathrm{NH}_{3}$ with $1.0 \mathrm{~mol}$ $\mathrm{L}^{-1} \mathrm{NH}_{4} \mathrm{Cl}$ were evaluated (Figure 4).

As for the loaded Cyanex 923, also $\mathrm{NH}_{3}$ could recover the tungsten, but with a poor phase separation, whereas, as for the loaded Aliquat 336, all stripping agents showed good phase separation with the loaded solvent, but only the binary mixture of $\mathrm{NH}_{3}$ and $\mathrm{NH}_{4} \mathrm{Cl}$ could strip the tungsten. The latter findings suggest an important role of both $\mathrm{NH}_{3}$ and $\mathrm{NH}_{4} \mathrm{Cl}$ during the tungsten stripping. In fact, $\mathrm{NH}_{3}$ guarantees the proper equilibrium $\mathrm{pH}>9$ to convert the extracted tungsten species to ammonium tungstate, $\left(\mathrm{NH}_{4}\right)_{2} \mathrm{WO}_{4}$; meanwhile, 

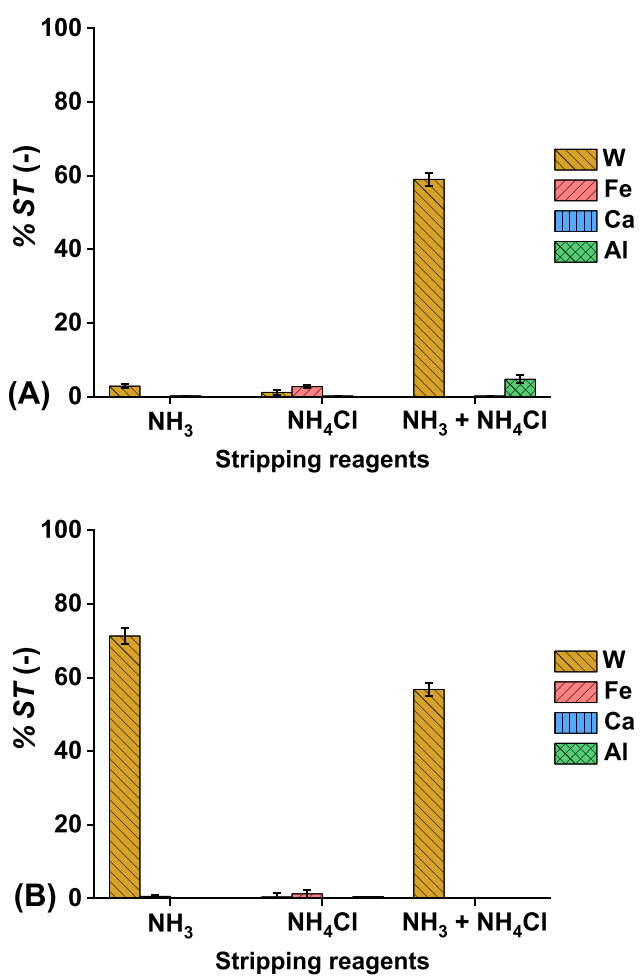

Figure 4. Stripping percentage, \%ST, of metals in $1.0 \mathrm{~mol} \mathrm{~L}^{-1} \mathrm{NH}_{3}$, $1.0 \mathrm{~mol} \mathrm{~L}^{-1} \mathrm{NH}_{4} \mathrm{Cl}$, or mixture of $1.0 \mathrm{~mol} \mathrm{~L}^{-1} \mathrm{NH}_{3}$ and $1.0 \mathrm{NH}_{4} \mathrm{Cl}$ from (A) the loaded Aliquat 336 and (B) Cyanex 923 in GS190 with $10 \mathrm{vol} \% 1$-decanol. Working conditions: MP $/ \mathrm{LP}$ ratio $=1 / 1 ; t=1 \mathrm{~h}$; $r=2000 \mathrm{rpm} ; T=$ room temperature.

$\mathrm{NH}_{4} \mathrm{Cl}$ provides the chloride as counterions for the Aliquat 336 regeneration.

As a result of the NASX screening tests from model solutions, Aliquat 336 was chosen as an extractant over Cyanex 923 because of the more efficient iron(III) scrubbing and the good stripping efficiency using a buffer solution of $\mathrm{NH}_{3}$ / $\mathrm{NH}_{4} \mathrm{Cl}$. Subsequently, the NASX process to recover tungsten from a $2 \mathrm{~mol} \mathrm{~L}^{-1} \mathrm{HCl}_{\mathrm{aq}} / \mathrm{EG}$ real leachate was optimized for the Aliquat 336 solvent. ${ }^{34-39}$ The effects of several diluents and the addition of a phase modifier are shown in Figure 5.

The nature of the diluent has a negligible effect on the $\% E_{S X}$ of $\mathrm{W}$ and $\mathrm{Fe}$, while it was observed that the presence of a phase modifier suppresses the extraction of impurities such as calcium and aluminum. The aromatic A-grade solvents provided a better phase separation. However, the aliphatic diluent, for example, Shell GTL Solvent GS190 was selected for further study because it has a lower environmental impact thanks to its high purity, low aromatic, low naphthenic contents, and low odor level. Once the diluent was selected, the concentration of extractant was optimized (Figure 6) and the stoichiometric ratio of extractant/metal for the NASX of tungsten via Aliquat 336 was estimated via slope analysis (Figure 7).

The $\% E_{\mathrm{SX}}$ of tungsten progressively increased, in a single stage, from 38.0 to 93.0 when the Aliquat 336 concentration increased from 0.1 to $0.8 \mathrm{~mol} \mathrm{~L}^{-1}$ (Figure 6). Meanwhile, a slight increase in extraction efficiency from 93.0 to 95.0 was achieved by varying the Aliquat 336 concentration in the range of $0.8-1.0 \mathrm{~mol} \mathrm{~L}^{-1}$. It should be noted that the higher the extractant concentration, the higher the increase of the viscosity of LP. To avoid problems in phase separation and
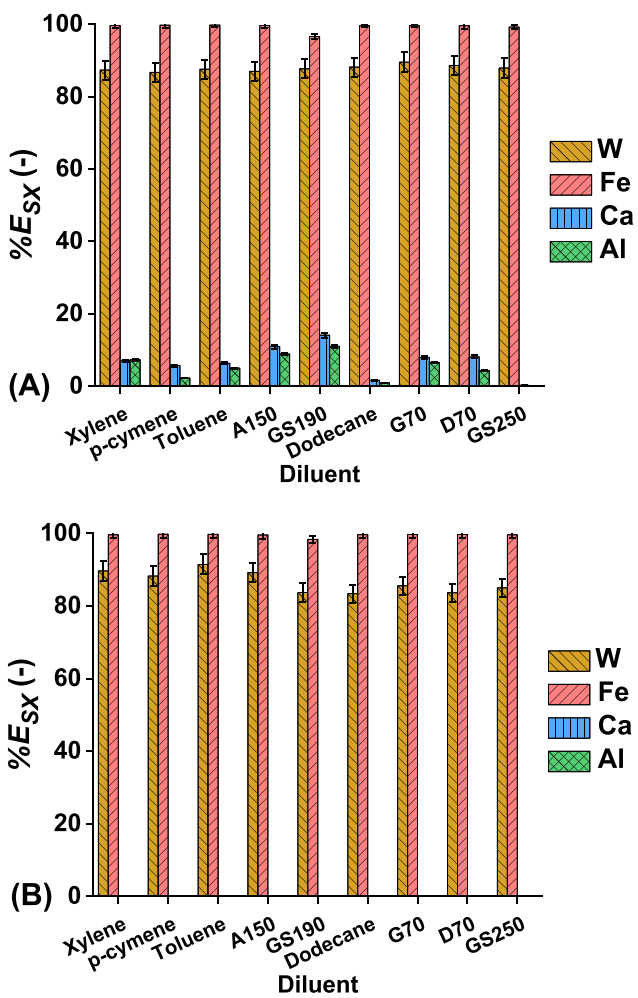

Figure 5. (A) Effect of aromatic and aliphatic diluents without phase modifier and (B) of addition of $10 \mathrm{vol} \% 1$-decanol on the NASX in Aliquat 336 of tungsten, iron, calcium, and aluminum from a $2 \mathrm{~mol}$ $\mathrm{L}^{-1} \mathrm{HCl}_{\mathrm{aq}} / \mathrm{EG}$ leachate with $2 \mathrm{~mol} \mathrm{~L} \mathrm{CaCl}_{2}$. Working conditions: $\mathrm{MP} / \mathrm{LP}$ ratio $=1 / 1 ; t=1 \mathrm{~h} ; r=2000 \mathrm{rpm} ; T=$ room temperature.

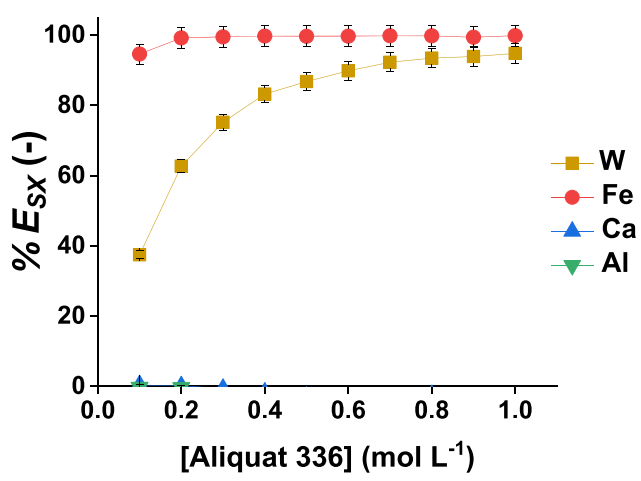

Figure 6. Effect of Aliquat 336 concentration in GS190 with 10 vol \% 1-decanol on the NASX of on the NASX of tungsten, iron, calcium, and aluminum from a $2 \mathrm{~mol} \mathrm{~L}^{-1} \mathrm{HCl}_{\mathrm{aq}} / \mathrm{EG}$ leachate with $2 \mathrm{~mol} \mathrm{~L}^{-1}$ $\mathrm{CaCl}_{2}$. Working conditions: $\mathrm{MP} / \mathrm{LP}$ ratio $=1 / 1 ; t=1 \mathrm{~h} ; r=2000$ rpm; $T$ = room temperature.

mass transfer, a concentration ranging between 0.47 and 0.71 mol L ${ }^{-1}$ Aliquat 336 (corresponding to 20 and 30 vol \%, respectively) was chosen as optimum to ensure a good $\% E_{\mathrm{SX}}$ of tungsten and a feasible solvent viscosity. Iron(III) was, unfortunately, efficiently extracted at any concentration of Aliquat 336, confirming the high affinity of this extractant for iron(III) and for other light transition metals in general. ${ }^{40-43}$

The mechanism of NASX entails an interesting research question and, so far, no conclusive answer has been reported. The composition of the extracted species was determined using the slope method. As shown in Figure 7, the plot of $\log D$ vs $\log$ [Aliquat 336] shows a straight line with a slope of 1.3 , 


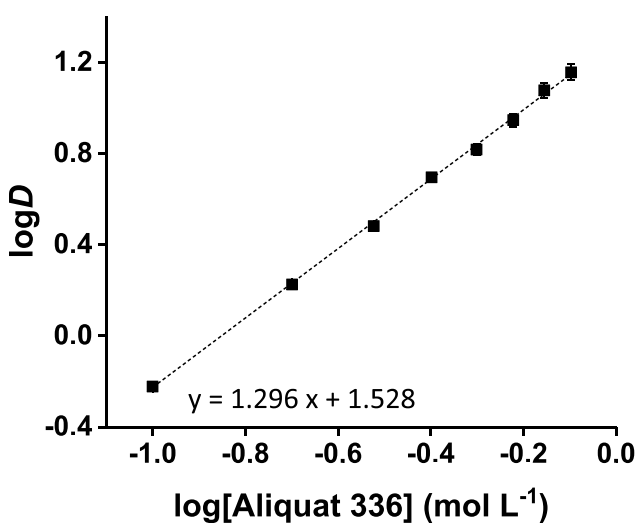

Figure 7. $\log D$ vs $\log [\mathrm{A} 336]$ for the NASX of tungsten in Aliquat 336 diluted in GS190 with $10 \mathrm{vol} \%$ 1-decanol from a $2 \mathrm{~mol} \mathrm{~L} \mathrm{HCl}_{\mathrm{aq}} /$ EG leachate with $2 \mathrm{~mol} \mathrm{~L}^{-1} \mathrm{CaCl}_{2}$. Working conditions: $\mathrm{MP} / \mathrm{LP}$ ratio $=1 / 1 ; t=1 \mathrm{~h} ; r=2000 \mathrm{rpm} ; T=$ room temperature.

suggesting that at least one mole of Aliquat 336 is needed to extract and coordinate one mole of the extracted species in the LP phase. The determined stoichiometric ratio tungsten/ Aliquat 336 for the NASX mechanism matches well with the one reported in traditional solvent extraction of tungsten via anion exchange. ${ }^{34,44-46}$ In aqueous solutions, tungsten tends to form isopolyanions and it is, in fact, extracted as isopolytungstate. ${ }^{45,46}$ No evidence exists that the same isopolytungstate species form in EG media, and the NASX mechanism can be assumed as reported in eq 8 for a generic tungstate anion. Equation 8 was postulated on the assumption that the linear behavior of the curve in Figure 7 likely implies that the tungsten species does not change upon extraction, or at least the number of tungsten centers per extracted species does not. The number of theoretical stages for NASX of tungsten was estimated by constructing McCabe-Thiele diagrams for concentrations of 20 vol.\% (Figure 8A) and 30 vol.\% (Figure 8B) Aliquat 336 in GS190.

$$
\mathrm{H}_{x} \mathrm{~W}_{y} \mathrm{O}_{z}^{n-}+n \overline{\left[\mathrm{R}_{3} \mathrm{R}^{\prime} \mathrm{N}\right] \mathrm{Cl}} \rightarrow \overline{\left[\mathrm{R}_{3} \mathrm{R}^{\prime} \mathrm{N}\right]_{n}\left[\mathrm{H}_{x} \mathrm{~W}_{y} \mathrm{O}_{z}\right]}+n \mathrm{Cl}^{-}
$$

Increasing the Aliquat 336 concentration from 20 to 30 vol.\% only has an effect on the number of theoretical stages at an $\mathrm{LP} / \mathrm{MP}$ phase ratio of $1 / 2$, i.e., when attempting to concentrate the tungsten through the NASX step, but not at the $\mathrm{LP} / \mathrm{MP}$ ratio of $1 / 1$. Under similar conditions, the use of 30 vol.\% Aliquat 336 required fewer stages (4 instead of 5) than those required with 20 vol.\% Aliquat 336. Taking into account the extraction efficiency, the number of theoretical countercurrent stages, the solvent losses per stage, and the chemical consumptions, 20 vol.\% Aliquat was considered as the optimum concentration at an LP/MP ratio of $1 / 1$. Subsequently, a batch-wise simulation of extraction with three countercurrent stages confirmed that tungsten and iron(III) were quantitatively extracted from the MP feed solution, leaving trace amounts of $0.03 \mathrm{~g} \mathrm{~L}^{-1}$ tungsten and $0.001 \mathrm{~g} \mathrm{~L}^{-1}$ iron in the MP raffinate phase. As for the scrubbing, $90 \%$ iron(III) is removed by contacting the loaded Aliquat 336 solvent with water at an $\mathrm{O} / \mathrm{A}$ phase ratio of $1 / 1$. Complete back-extraction of iron(III) can be achieved using either two stages $(O / A=1 / 1)$ or single stage $(O / A=1 / 2)$ for $1 \mathrm{~h}$, at room temperature, and $2000 \mathrm{rpm}$. Note that although the reaction rates for NASX and scrubbing were rather fast
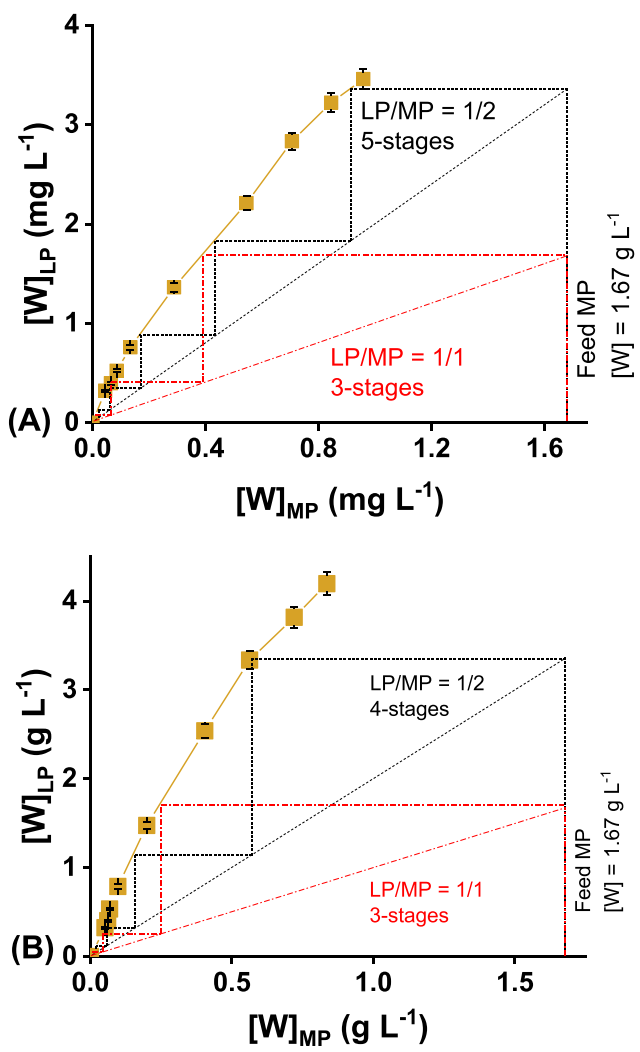

Figure 8. McCabe-Thiele diagrams for the NASX of tungsten in (A) $20 \mathrm{vol} \%$ and (B) $30 \mathrm{vol} \%$ Aliquat 336 in GS190 with 10 vol \% 1decanol from a $2 \mathrm{~mol} \mathrm{~L}^{-1} \mathrm{HCl}_{\mathrm{aq}} / \mathrm{EG}$ leachate with $2 \mathrm{~mol} \mathrm{~L}^{-1} \mathrm{CaCl}_{2}$. Working conditions: $t=1 \mathrm{~h} ; r=2000 \mathrm{rpm} ; T=$ room temperature.

(within $5 \mathrm{~min}$ ), all experiments were performed for $1 \mathrm{~h}$ to ensure that full equilibrium was achieved.

Finally, stripping of tungsten was optimized. It has been already shown (Figure 4) that mixtures of $\mathrm{NH}_{3}-\mathrm{NH}_{4} \mathrm{Cl}$ efficiently strip tungsten from the loaded Aliquat 336 solvent. In addition, the concentrations of both $\mathrm{NH}_{3}$ and $\mathrm{NH}_{4} \mathrm{Cl}$ were separately optimized, keeping the concentration of one component at $1.0 \mathrm{~mol} \mathrm{~L}^{-1}$ while varying the other. The results are shown in Figure 9.

A plateau is reached for both $\mathrm{NH}_{3}$ and $\mathrm{NH}_{4} \mathrm{Cl}$ and at the same concentration of $1.0 \mathrm{~mol} \mathrm{~L}^{-1}$, indicating that tungsten is efficiently stripped in solutions of both $\mathrm{NH}_{3}$ and $\mathrm{NH}_{4} \mathrm{Cl}$. In the case of tertiary amines, such as TOA, aqueous $\mathrm{NH}_{3}$ is enough to recover tungsten because the conjugate acid of the tertiary amine will deprotonate at a high $\mathrm{pH}$, inhibiting further extraction. Charge neutrality is preserved by co-stripping of these protons. Quaternary ammonium compounds, such as Aliquat 336, require the presence of chloride anions, which are efficiently exchanged for the highly hydrated tungstate dianions, hence preserving the charge neutrality of both phases upon stripping by anion exchange. We targeted to obtain $\left(\mathrm{NH}_{4}\right)_{2} \mathrm{WO}_{4}$, which can subsequently be converted to APT by evaporation and crystallization. The stripping mechanism was first described by Gaur and is given in eq 9. ${ }^{46}$ This equation refers, similarly to eq 8 , to a generic polytungstate $\mathrm{H}_{x} \mathrm{~W}_{y} \mathrm{O}_{z}{ }^{n-}$ as the extracted species; moreover, the equation does not include the stripping agents $\mathrm{NH}_{3}$ and $\mathrm{NH}_{4} \mathrm{Cl}$ but the $\mathrm{OH}^{-}$and $\mathrm{Cl}^{-}$ions, provided by, respectively, $\mathrm{NH}_{3}$ and $\mathrm{NH}_{4} \mathrm{Cl} . \mathrm{NH}_{3}$ works to provide $\mathrm{OH}$ ions, which decompose the polytungstate species. 

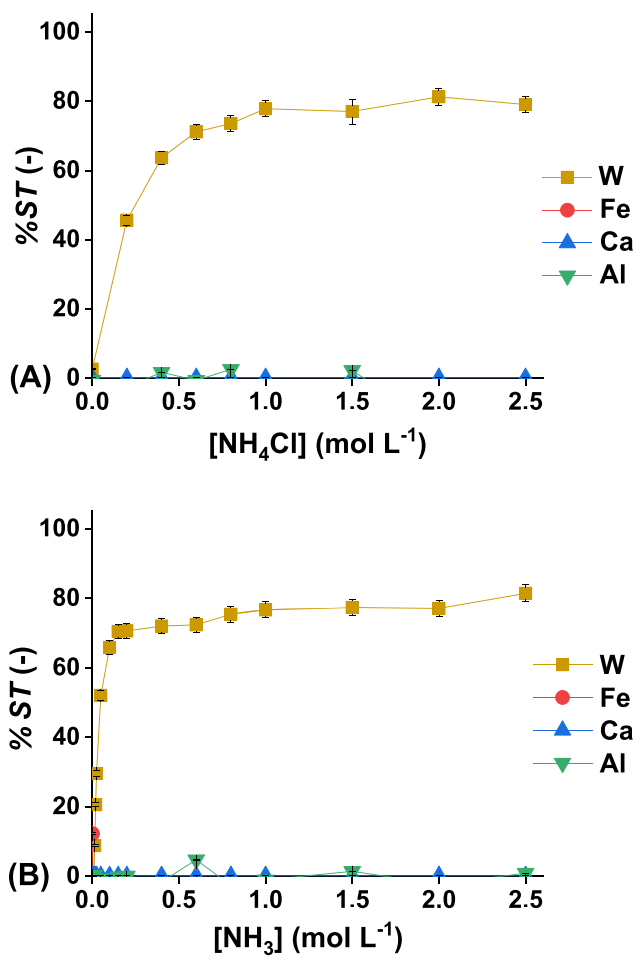

Figure 9. (A) Optimization of $\mathrm{NH}_{4} \mathrm{Cl}$ concentration $\left(\left[\mathrm{NH}_{3}\right]=1 \mathrm{~mol}\right.$ $\left.\mathrm{L}^{-1}\right)$ and $(\mathrm{B}) \mathrm{NH}_{3}$ concentration $\left(\left[\mathrm{NH}_{4} \mathrm{Cl}\right]=1 \mathrm{~mol} \mathrm{~L}^{-1}\right)$ for the selective stripping of tungsten from loaded $20 \mathrm{vol} \%$ Aliquat 336 in GS190 with 10 vol $\%$ 1-decanol. Working conditions: O/A ratio $=1$ / $1 ; t=1 \mathrm{~h} ; r=2000 \mathrm{rpm} ; T=$ room temperature.

Once the stripping solution was defined as $1.0 \mathrm{~mol} \mathrm{~L}^{-1} \mathrm{NH}_{3}$ with $1.0 \mathrm{~mol} \mathrm{~L}^{-1} \mathrm{NH}_{4} \mathrm{Cl}$, McCabe-Thiele diagrams systems were constructed to calculate the theoretical number of stages at two different $\mathrm{O} / \mathrm{A}$ ratios, $1 / 1$ and 3/1 (Figure 10).

$$
\begin{gathered}
m{\overline{\left[\mathrm{R}_{3} \mathrm{R}^{\prime} \mathrm{N}\right]_{n}\left[\mathrm{H}_{x} \mathrm{~W}_{y} \mathrm{O}_{z}\right]}}_{\text {org }}+q \mathrm{OH}_{\mathrm{aq}}^{-}+(m \cdot n) \mathrm{Cl}_{\mathrm{aq}}^{-} \\
\rightarrow \mathrm{WO}_{4}^{2-}{ }_{\mathrm{aq}}+r \mathrm{H}_{2} \mathrm{O}+(m \cdot n) \overline{\left[\mathrm{R}_{3} \mathrm{R}^{\prime} \mathrm{N}\right][\mathrm{Cl}]}{ }_{\text {org }}
\end{gathered}
$$

The diagrams showed an intersection of the stripping isotherm with the operating lines at both $\mathrm{O} / \mathrm{A}$ ratios $1 / 1$ and $3 / 1$. It means that it is challenging to get less than about $0.30 \mathrm{~g} \mathrm{~L}^{-1}$ tungsten in the organic phase using a mixture of $1.0 \mathrm{~mol} \mathrm{~L}^{-1}$ $\mathrm{NH}_{3}$ and $1.0 \mathrm{~mol} \mathrm{~L}^{-1} \mathrm{NH}_{4} \mathrm{Cl}$ in a countercurrent system. Similarly to the NASX step, a countercurrent process was simulated in batch at $\mathrm{O} / \mathrm{A}=3 / 1$, confirming that, after three stages, the tungsten concentration is $0.33 \mathrm{~g} \mathrm{~L}^{-1}$ in the loaded solvent and $2.71 \mathrm{~g} \mathrm{~L}^{-1}$ in the $\mathrm{NH}_{3}-\mathrm{NH}_{4} \mathrm{Cl}$ stripped phase. However, quantitative stripping will be possible if operating in cross-current mode. Furthermore, the stripping efficiency of tungsten can be enhanced by increasing either the concentration of $\mathrm{NH}_{3} / \mathrm{NH}_{4} \mathrm{Cl}$ or the temperature up to $60^{\circ} \mathrm{C}$ (Figure S10).

In the light of the obtained results, a conceptual flowsheet has been suggested for the solvometallurgical recovery of tungsten from $\mathrm{CaWO}_{4}$ contained in high-grade (ca. $55.0 \mathrm{wt} \%$ $\mathrm{W}$ ) and medium-grade (ca. $3.3 \mathrm{wt} \% \mathrm{~W}$ ) ores (Figure 11). The overall tungsten recovery is between 55 and $60 \%$ if operating the NASX in a single-stage process, but it will increase when running the process in multistages in mixer-settlers. One drawback is the potential formation of trace levels of 2chloroethanol, in the leaching stage. However, this problem
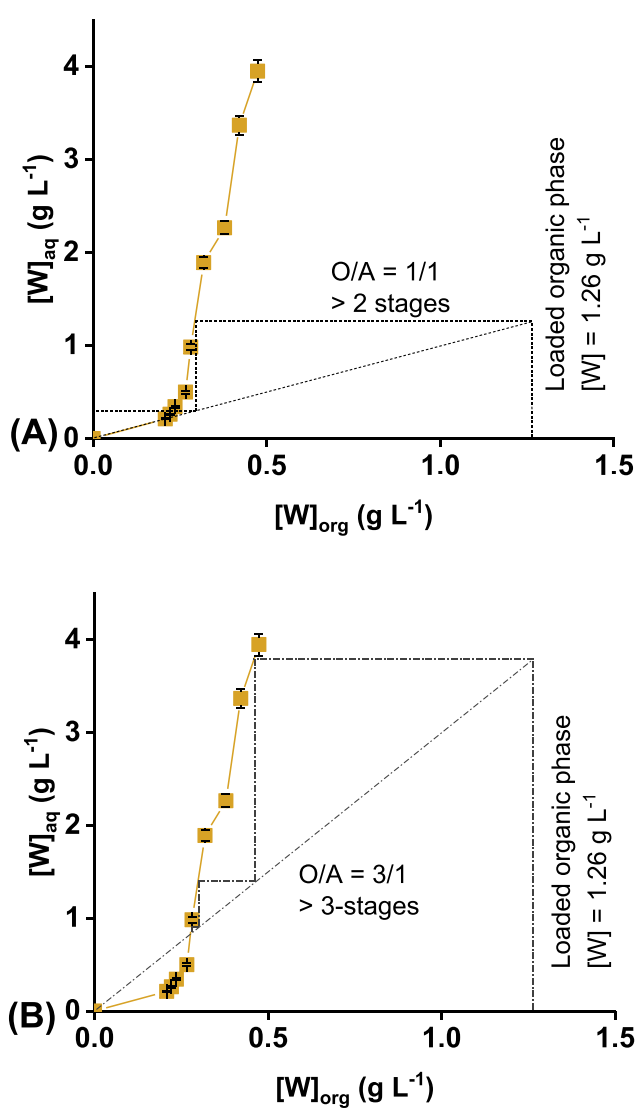

Figure 10. (A) McCabe-Thiele diagrams for the stripping of tungsten in a mixture of $1.0 \mathrm{~mol} \mathrm{~L}^{-1} \mathrm{NH}_{3}$ and $1.0 \mathrm{~mol} \mathrm{~L}^{-1} \mathrm{NH}_{4} \mathrm{Cl}$ from 20 vol \% Aliquat 336 in GS190 with 10 vol \% 1-decanol at O/A ratio $=1 / 1$ and $(\mathrm{B})$ at $\mathrm{O} / \mathrm{A}$ ratio $=3 / 1$. Other working conditions: $t=$ $1 \mathrm{~h} ; r=2000 \mathrm{rpm} ; \mathrm{T}=$ room temperature.

can be avoided by further optimizing process conditions, such as a better mixing of the solid and the lixiviant to enhance the mass transfer and reduce the reaction time.

\section{CONCLUSIONS}

In the current paper, we developed a conceptual flowsheet that comprises solvoleaching of tungsten from scheelite $\left(\mathrm{CaWO}_{4}\right)$ in $2 \mathrm{~mol} \mathrm{~L}^{-1} \mathrm{HCl}_{\mathrm{aq}}$ in ethylene glycol, and nonaqueous solvent extraction of tungsten from the $\mathrm{HCl}-$ ethylene glycol leachate using 20 vol \% Aliquat 336 in the aliphatic diluent Shell GTL Solvent GS190 with 10 vol \% 1-decanol. Thereafter, tungsten is recovered as ammonium tungstate in solutions of $1.0 \mathrm{~mol}$ $\mathrm{L}^{-1} \mathrm{NH}_{3, \mathrm{aq}}$ with $1.0 \mathrm{~mol} \mathrm{~L} \mathrm{LH}_{4} \mathrm{Cl}$. Compared to the industrial state-of-the-art process-in which recovery of tungsten from $\mathrm{CaWO}_{4}$ is carried out in $\mathrm{NaOH} / \mathrm{Na}_{2} \mathrm{CO}_{3}$ solutions in an autoclave at temperatures around 190-225 ${ }^{\circ} \mathrm{C}$ and large volumes of high-salinity acidic wastewater are generated (up to 25 tons per ton of produced APT)-the main advantages of the present conceptual flowsheet are: (i) ethylene glycol avoids the precipitation of tungsten even in the presence of $2 \mathrm{~mol} \mathrm{~L}^{-1} \mathrm{HCl}_{\mathrm{aq}}$; (ii) consequently, no further steps of re-dissolution are required; (iii) selective NASX and scrubbing steps produce an organic phase with only tungsten present; and (iv) tungsten can be recovered from the loaded Aliquat 336 phase as ammonium tungstate, from which tungsten is commonly crystallized and purified as APT. Other advantages compared to the traditional industrial process are: (v) milder leaching conditions, i.e., no pressure 


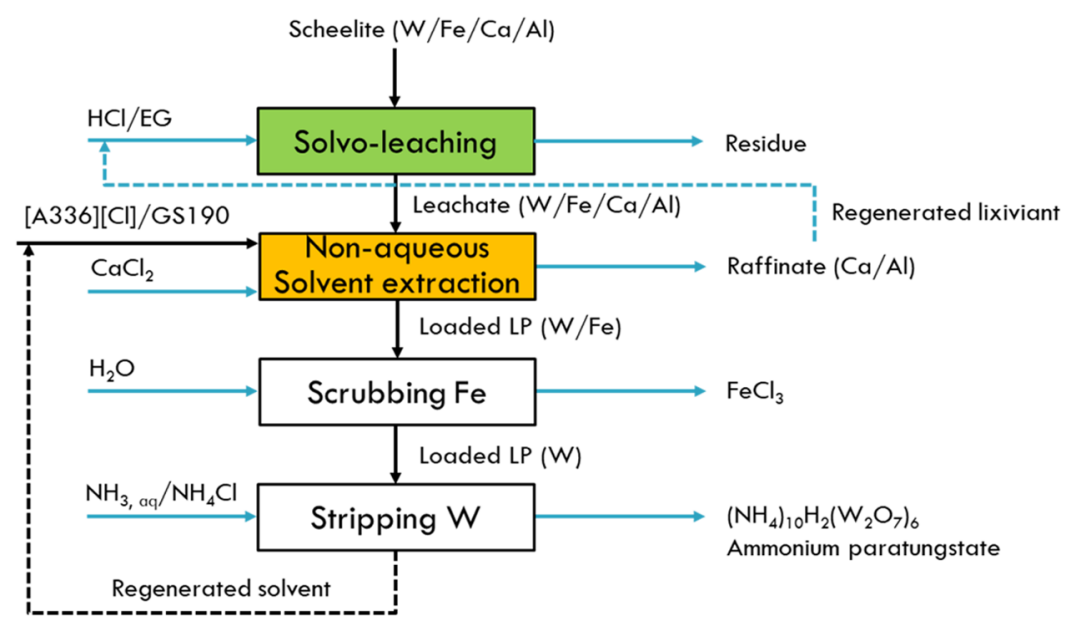

Figure 11. Conceptual flowsheet for the solvometallurgical recovery of tungsten from $\mathrm{CaWO}_{4}$ in high-grade $(W=55$ wt $\%)$ and medium-grade $(W$ $=3.3$ wt $\%$ ) ores.

above atmospheric pressure and no temperatures above 100 ${ }^{\circ} \mathrm{C}$, and (vi) no generation of high-salinity wastewater.

The nonaqueous solvent extraction system selectively extracts tungsten, leaving calcium in the raffinate. This is particularly convenient for streams like the scheelite leachates of this work, where calcium was the main impurity. In the case of streams such as the leachate of medium-grade scheelite, the other main impurity is iron and can be removed by scrubbing with water. The production of tungsten(VI) oxide or tungsten metal from the obtained ammonium tungstate has not been investigated since they can be carried out according to established industrial procedures. One drawback that needs to be adequately addressed, prior to further upscaling of this process, is the potential formation of trace levels of 2chloroethanol in the solvoleaching step. It is hypothesized that this problem can be circumvented by further optimizing process conditions, such as the mixing to enhance the solidliquid mass transfer and reduce the reaction time.

\section{ASSOCIATED CONTENT}

\section{SI Supporting Information}

The Supporting Information is available free of charge at https://pubs.acs.org/doi/10.1021/acs.iecr.1c03872.

Photos of the screening tests with $2-6 \mathrm{~mol} \mathrm{~L}^{-1} \mathrm{HCl}_{\mathrm{aq}}$, displaying the formation of yellow $\mathrm{H}_{2} \mathrm{WO}_{4}$ precipitate (Figures S1 and S2); ${ }^{1} \mathrm{H}$ NMR spectra of the $2 \mathrm{~mol} \mathrm{~L}^{-1}$ $\mathrm{HCl}_{\mathrm{aq}} / \mathrm{EG}$ solutions recorded in DMSO- $d_{6}$ with a Bruker Avance II+ $600 \mathrm{MHz}$ (Figures S3-S9); and plot over the increased tungsten stripping efficiency at a higher $\mathrm{NH}_{3} / \mathrm{NH}_{4} \mathrm{Cl}$ concentration or a higher temperature (Figure S10). (PDF)

\section{AUTHOR INFORMATION}

\section{Corresponding Author}

Martina Orefice - Department of Chemistry, KU Leuven, 3001 Leuven, Belgium; 이이.org/0000-0003-3854-9974; Email: martina.orefice@kuleuven.be

\section{Authors}

Viet Tu Nguyen - Department of Chemistry, KU Leuven, 3001 Leuven, Belgium; 이이이.org/0000-0002-9348-8011

Stijn Raiguel - Department of Chemistry, KU Leuven, 3001 Leuven, Belgium
Peter Tom Jones - Department of Materials Engineering, $\mathrm{KU}$ Leuven, 3001 Leuven, Belgium

Koen Binnemans - Department of Chemistry, KU Leuven, 3001 Leuven, Belgium; (1) orcid.org/0000-0003-4768-3606

Complete contact information is available at:

https://pubs.acs.org/10.1021/acs.iecr.1c03872

\section{Author Contributions}

${ }^{\S}$ M.O. and V.T.N. contributed equally to this work. The manuscript was written through contributions of all authors. All authors have given approval to the final version of the manuscript.

\section{Funding}

The research leading to these results received funding from the European Commission's Horizon 2020 Programme ([H2020/ 2014-2019]) under Grant Agreement no. 821159 (RIA TARANTULA). This publication reflects only the authors' view, exempting the Commission from any liability.

Notes

The authors declare no competing financial interest.

\section{ACKNOWLEDGMENTS}

The authors thank the colleagues at Saloro (Spain) and ULiège (Belgium) for providing and preconcentrating the samples. Bart Van Huffel is greatly acknowledged for having performed the ${ }^{1} \mathrm{H}$ NMR analysis on the Bruker Avance II+ $600 \mathrm{MHz}$ and Christine Wouters for the support in the GC/MS analysis.

\section{ABBREVIATIONS}

$\begin{array}{ll}55-\mathrm{W} & 55 \text { wt \% W sample } \\ 3-\mathrm{W} & 3.3 \mathrm{wt} \% \mathrm{~W} \text { sample } \\ \mathrm{APT} & \text { ammonium paratungstate } \\ \mathrm{HCl}_{\mathrm{aq}} / \mathrm{EG} & 37.0 \mathrm{wt} \% \text { aqueous } \mathrm{HCl} \text { in ethylene glycol } \\ \mathrm{LP} & \text { less polar phase } \\ \mathrm{MP} & \text { more polar phase } \\ \mathrm{NASX} & \text { nonaqueous solvent extraction } \\ \mathrm{O} / \mathrm{A} & \begin{array}{l}\text { organic/aqueous ratio } \\ \text { WC }\end{array} \\ \text { tungsten carbide }\end{array}$

\section{REFERENCES}

(1) U.S. Geological SurveyMineral Commodity Summaries; U.S. Geological Survey: Reston, VA, 2020. 
(2) JRC; European CommissionCritical Materials for Strategic Technologies and Sectors in the EU - A Foresight Study; Publications Office of the European Union: Luxembourg, 2020.

(3) European CommissionStudy on the EU's List of Critical Raw Materials; Publications Office of the European Union: Luxembourg, 2020.

(4) Lederer, G. W.; Solano, F.; Coyan, J. A.; Denton, K. M.; Watts, K. E.; Mercer, C. N.; Bickerstaff, D. P.; Granitto, M. Tungsten Skarn Mineral Resource Assessment of the Great Basin Region of Western Nevada and Eastern California. J. Geochem. Explor. 2021, 223, No. 106712

(5) Tkaczyk, A. H.; Bartl, A.; Amato, A.; Lapkovskis, V.; Petranikova, M. Sustainability Evaluation of Essential Critical Raw Materials: Cobalt, Niobium, Tungsten and Rare Earth Elements Sustainability Evaluation of Essential Critical Raw Materials: Cobalt, Niobium, Tungsten and Rare Earth Elements. J. Phys. D: Appl. Phys. 2018, 51, No. 203001

(6) Lassner, E.; Schubert, W.-D.; Luderitz, E.; Wolf, H. U. Tungsten, Tungsten Alloys, and Tungsten Compounds. In Ullmann's Encyclopedia of Industrial Chemistry; Wiley-VCH Verlag GmbH \& Co. KGaA: Weinheim, Germany, 2005.

(7) Shen, L.; Li, X.; Lindberg, D.; Taskinen, P. Tungsten Extractive Metallurgy: A Review of Processes and Their Challenges for Sustainability. Miner. Eng. 2019, 142, No. 105934.

(8) Furberg, A.; Arvidsson, R.; Molander, S. Environmental Life Cycle Assessment of Cemented Carbide (WC-Co) Production. J. Cleaner Prod. 2019, 209, 1126-1138.

(9) Xuin, G. H.; Yu, D. Y.; Su, Y. F. Leaching of Scheelite by Hydrochloric Acid in the Presence of Phosphate. Hydrometallurgy 1986, 16, 27-40.

(10) Gürmen, S.; Timur, S.; Arslan, C.; Duman, I. Acidic Leaching of Scheelite Concentrate and Production of Hetero-Poly-Tungstate Salt. Hydrometallurgy 1999, 51, 227-238.

(11) Gürmen, S.; Timur, S.; Arslan, C.; Duman, I. Production of Pure Tungsten Oxide from Scheelite Concentrates. Scand. J. Metall. 2002, 31, 221-228.

(12) Kahruman, C.; Yusufoglu, I. Leaching Kinetics of Synthetic $\mathrm{CaWO}_{4}$ in $\mathrm{HCl}$ Solutions Containing $\mathrm{H}_{3} \mathrm{PO}_{4}$ as Chelating Agent. Hydrometallurgy 2006, 81, 182-189.

(13) Kalpakli, A. O.; Ilhan, S.; Kahruman, C.; Yusufoglu, I. Thermal Decomposition Mechanism of Ammonium Phosphotungstate Hydrate in Air Atmosphere. Int. J. Refract. Met. Hard Mater. 2012, 31, 14-20.

(14) Razavizadeh, H.; Iangroudi, A. E. Production of Tungsten via Leaching of Scheelite with Sulfuric Acid. Min. Metall. Explor. 2006, $23,67-72$.

(15) Zhao, Z.; Li, J. Method for Extracting Tungsten from Scheelite. U.S. Patent US8,771,617B2, 2014.

(16) Li, J.; Zhao, Z. Kinetics of Scheelite Concentrate Digestion with Sulfuric Acid in the Presence of Phosphoric Acid. Hydrometallurgy 2016, 163, 55-60.

(17) Li, X. B.; Cui, Y. F.; Zhou, Q. S.; Li, J. P.; Qi, T. G.; Xu, S.; Liu, G. H.; Lin, G. R.; Peng, Z. H.; Li, J. H.; Xu, X. M.; Shen, L. T. System for Preparing APT (Ammonium Paratungstate) from Tungsten Mineral Raw Material with Zero Pollution. Chinese Patent CN104263971, 2014

(18) Li, X. B.; Cui, Y. F.; Zhou, Q. S.; Li, J. P.; Qi, T. G.; Xu, S.; Liu, G. H.; Lin, G. R.; Peng, Z. H.; Li, J. H.; Xu, X. M.; Shen, L. T. ZeroPollutant-Discharge Metallurgical Technology for Tungsten Mineral Raw Material. Chinese Patent CN104263923, 2014.

(19) Li, X.; Shen, L.; Zhou, Q.; Peng, Z.; Liu, G.; Qi, T. Scheelite Conversion in Sulfuric Acid Together with Tungsten Extraction by Ammonium Carbonate Solution. Hydrometallurgy 2017, 171, 106115.

(20) Shen, L.; Li, X.; Zhou, Q.; Peng, Z.; Liu, G.; Qi, T.; Taskinen, P. Sustainable and Efficient Leaching of Tungsten in Ammoniacal Ammonium Carbonate Solution from the Sulfuric Acid Converted Product of Scheelite. J. Cleaner Prod. 2018, 197, 690-698.
(21) Forward, F. A.; Vizsolyi, A. I. Process for the Production of Tungstic Acid. U.S. Patent US3,193,347, 1965.

(22) Gong, D.; Zhou, K.; Peng, C.; He, D.; Chen, W. ResinEnhanced Acid Leaching of Tungsten from Scheelite. Hydrometallurgy 2018, 182, 75-81.

(23) Sun, P.-M.; Li, H.-G.; Li, Y.-J.; Zhao, Z.-W.; Huo, G.-S.; Sun, Z.-M.; Liu, M.-S. Decomposing Scheelite and Scheelite-Wolframite Mixed Concentrate by Caustic Soda Digestion. J. Cent. South Univ. Technol. 2003, 10, 297-300.

(24) Zhao, Z.; Li, J.; Wang, S.; Li, H.; Liu, M.; Sun, P.; Li, Y. Extracting Tungsten from Scheelite Concentrate with Caustic Soda by Autoclaving Process. Hydrometallurgy 2011, 108, 152-156.

(25) Zhao, Z.; Liang, Y.; Li, H. Kinetics of Sodium Hydroxide Leaching of Scheelite. Int. J. Refract. Met. Hard Mater. 2011, 29, 289292.

(26) Zhao, Z.; Liang, Y.; Liu, X.; Chen, A.; Li, H. Sodium Hydroxide Digestion of Scheelite by Reactive Extrusion. Int. J. Refract. Met. Hard Mater. 2011, 29, 739-742.

(27) Zhang, G.; Guan, W.; Xiao, L.; Zhang, Q. A Novel Process for Tungsten Hydrometallurgy Based on Direct Solvent Extraction in Alkaline Medium. Hydrometallurgy 2016, 165, 233-237.

(28) Gong, D.; Zhou, K.; Peng, C.; Li, J.; Chen, W. Sequential Extraction of Tungsten from Scheelite through Roasting and Alkaline Leaching. Miner. Eng. 2019, 132, 238-244.

(29) Martins, J. I.; Moreira, A.; Costa, S. C. Leaching of Synthetic Scheelite by Hydrochloric Acid without the Formation of Tungstic Acid. Hydrometallurgy 2003, 70, 131-141.

(30) Martins, J. I. Leaching Systems of Wolframite and Scheelite: A Thermodynamic Approach. Miner. Process. Extr. Metall. Rev. 2014, 35, $23-43$.

(31) Surls, J. P. J.; Creek, W. Process for the Recovery of Tungsten from Its Ores. U.S. Patent US3,271,104, 1966.

(32) Özdemir, S.; Girgin, I. Decomposition of Scheelite in AcidAlcohol Solutions. Miner. Eng. 1991, 4, 179-184.

(33) Girgin, I.; Erkal, F. Dissolution Characteristics of Scheelite in $\mathrm{HCl}-\mathrm{C}_{2} \mathrm{H}_{5} \mathrm{OH}-\mathrm{H}_{2} \mathrm{O}$ and $\mathrm{HCl}-\mathrm{C}_{2} \mathrm{H}_{5} \mathrm{OH}$ Solutions. Hydrometallurgy 1993, 34, 221-230.

(34) Cueva Sola, A. B.; Parhi, P. K.; Lee, J. Y.; Kang, H. N.; Jyothi, R. K. Environmentally Friendly Approach to Recover Vanadium and Tungsten from Spent SCR Catalyst Leach Liquors Using Aliquat 336. RSC Adv. 2020, 10, 19736-19746.

(35) Lende, A. B.; Kulkarni, P. S. Selective Recovery of Tungsten from Printed Circuit Board Recycling Unit Wastewater by Using Emulsion Liquid Membrane Process. J. Water Process Eng. 2015, 8, $75-81$.

(36) Nguyen, T. H.; Lee, M. S. Separation of Vanadium and Tungsten from Sodium Molybdate Solution by Solvent Extraction. Ind. Eng. Chem. Res. 2014, 53, 8608-8614.

(37) Sato, T.; Sato, K. Liquid-Liquid Extraction of Tungsten(VI) from Hydrochloric Acid Solutions by Neutral Organophosphorus Compounds and High Molecular Weight Amines. Hydrometallutgy 1995, 37, 253.

(38) Guedes De Carvalho, R. A.; Sampaio, M. N. M. Solvent Extraction of Tungsten by Alkylamines Hydrochloric Acid and Alkylamines-Sulphuric Acid Systems. Hydrometallurgy 1991, 26, 137150 .

(39) Das, N. R.; Chattopadhyay, P. Solvent and Reversed Phase Extraction Chromatographic Separation of Molybdenum and Tungsten with Quaternary Ammonium Salt Reagent, Aliquat 336. Bull. Chem. Soc. Jpn. 1989, 62, 3278-3282.

(40) Liu, Z.; Huang, J.; Zhang, Y.; Liu, T.; Hu, P.; Liu, H.; Zheng, Q. Separation and Recovery of Vanadium and Iron from Oxalic-AcidBased Shale Leachate by Coextraction and Stepwise Stripping. Sep. Purif. Technol. 2020, 244, No. 116532.

(41) Orefice, M.; Audoor, H.; Li, Z.; Binnemans, K. Solvometallurgical Route for the Recovery of $\mathrm{Sm}, \mathrm{Co}, \mathrm{Cu}$ and $\mathrm{Fe}$ from $\mathrm{SmCo}$ Permanent Magnets. Sep. Purif. Technol. 2019, 219, 281-289.

(42) Li, Z.; Li, X.; Raiguel, S.; Binnemans, K. Separation of Transition Metals from Rare Earths by Non-Aqueous Solvent 
Extraction from Ethylene Glycol Solutions Using Aliquat 336. Sep. Purif. Technol. 2018, 201, 318-326.

(43) Mishra, R. K.; Rout, P. C.; Sarangi, K.; Nathsarma, K. C. Solvent Extraction of Fe(III) from the Chloride Leach Liquor of Low Grade Iron Ore Tailings Using Aliquat 336. Hydrometallurgy 2011, 108, 93-99.

(44) Yang, Y.; Xie, B.; Wang, R.; Xu, S.; Wang, J.; Xu, Z. Extraction and Separation of Tungsten from Acidic High-Phosphorus Solution. Hydrometallurgy 2016, 164, 97-102.

(45) Nguyen, T. H.; Lee, M. S. A Review on the Separation of Molybdenum, Tungsten, and Vanadium from Leach Liquors of Diverse Resources by Solvent Extraction. Geosyst. Eng. 2016, 19, 247259.

(46) Gaur, R. P. S. Modern Hydrometallurgical Production Methods for Tungsten. JOM 2006, 58, 45-49.

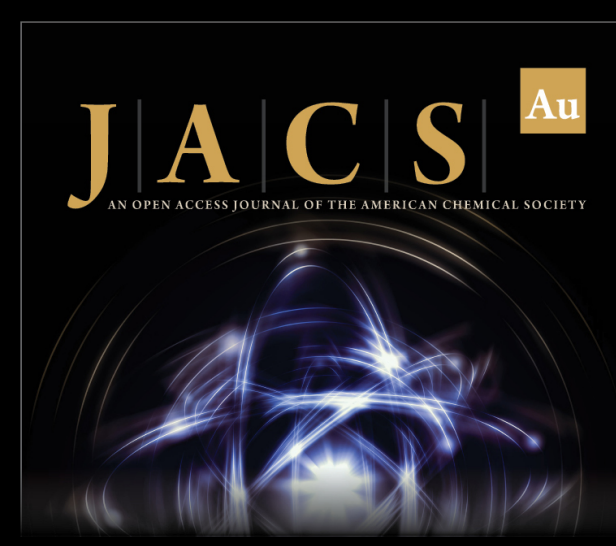

Editor-in-Chief

Prof. Christopher W. Jones

Georgia Institute of Technology, USA

Open for Submissions 